\title{
On Flexural Stiffness of Polymer Sandwich Walls
}

\author{
ŠUBA Oldřich ${ }^{1, a}$, FOJTL Ladislavi, ${ }^{1, b}$, ŠUBA Oldřich jr. . $^{1, c}$, SÝKOROVÁ \\ Libuše ${ }^{1, \mathrm{~d}}$, RUSNÁKOVÁ Soňa ${ }^{1, \mathrm{e}}$, BAĎUROVÁ Jitka ${ }^{1, f}$ \\ ${ }^{1}$ Tomas Bata University in Zlin, Faculty of Technology, Vavrečkova 275, 76001 Zlín, Czech \\ Republic \\ asuba@ft.utb.cz, bfojt|@ft.utb.cz, cosuba@ft.utb.cz, ${ }^{\mathrm{d}}$ sykorova@ft.utb.cz, erusnakova@ft.utb.cz, \\ fbadurova@ft.utb.cz
}

Keywords: Sandwich materials, flexural stiffness, analytical solutions, FEM solutions, bending, composite materials

\begin{abstract}
This paper deals with the flexural stiffness of sandwich structures based on fiberglass and polymeric foams. The influence of geometrical and material parameters on the resulting effective flexural stiffness of the sandwich structure is being studied experimentally, analytically and using FEM models. The effective elasticity module of the sandwich-structured element is being studied and it's theoretical and model dependencies on the stiffness of the foam core are being investigated. These dependencies are then compared with experimentally observed values. This study shows it is necessary to pay special attention to the issue of flexural stiffness of walls when designing sandwich shell products in order to prevent possible failures in the practical applications of these types of structures.
\end{abstract}

\section{Introduction}

Manufacturing technologies together with polymer based sandwich structure properties description show permanent rise and therefore are main subject of many researches [1,2]. Technological process itself is relatively demanding, however, as the result a structure with high flexural stiffness and load capacity is obtained [3]. Moreover, manufacturing is effective even for small production series due its low cost for the production of wood, gypsum or laminate mold [4].

Each successful application of plastic based engineering composites is conditioned beside thorough construction and technological preparation by qualified determination of dimensions and shape of the designed construction. Specificity of the plastics mechanical brings peculiarities and difficulties in designing compared to conventional constructions. The character of technology and efforts to reduce the product weight and eventually price lead to the design of plastics and composites as the thin-walled shells. In the case of classic - homogenous plastic or laminate structure, the ratio of stiffness to strength is considerably low, thus in many cases, limit states are crucial for the product design, related to the wall stiffness, rather than its strength automotive [5]. In cases of loads that cause compression membrane stresses in shell wall, limit states of shell stability loss, which are connected to bending stiffness of its wall, are crucial for the shell design. Traditional applications, where is possible to find these layered materials are facing panels in transport vehicles, boat hulls, wing parts of passenger aircrafts or roof and floors elements in automotive [6-8].

Structural sandwich construction (Fig. 1) is defined as a special type of layered composite, consisting of two thin, stiff and strong face sheets (facings), between which a light, but according to the mechanical properties weaker core of defined thickness is placed. The basic concept of sandwich structure assumes that face sheets transmit normal stresses from bending moments, while core transmits shear stresses from transverse forces $[4,9]$. 

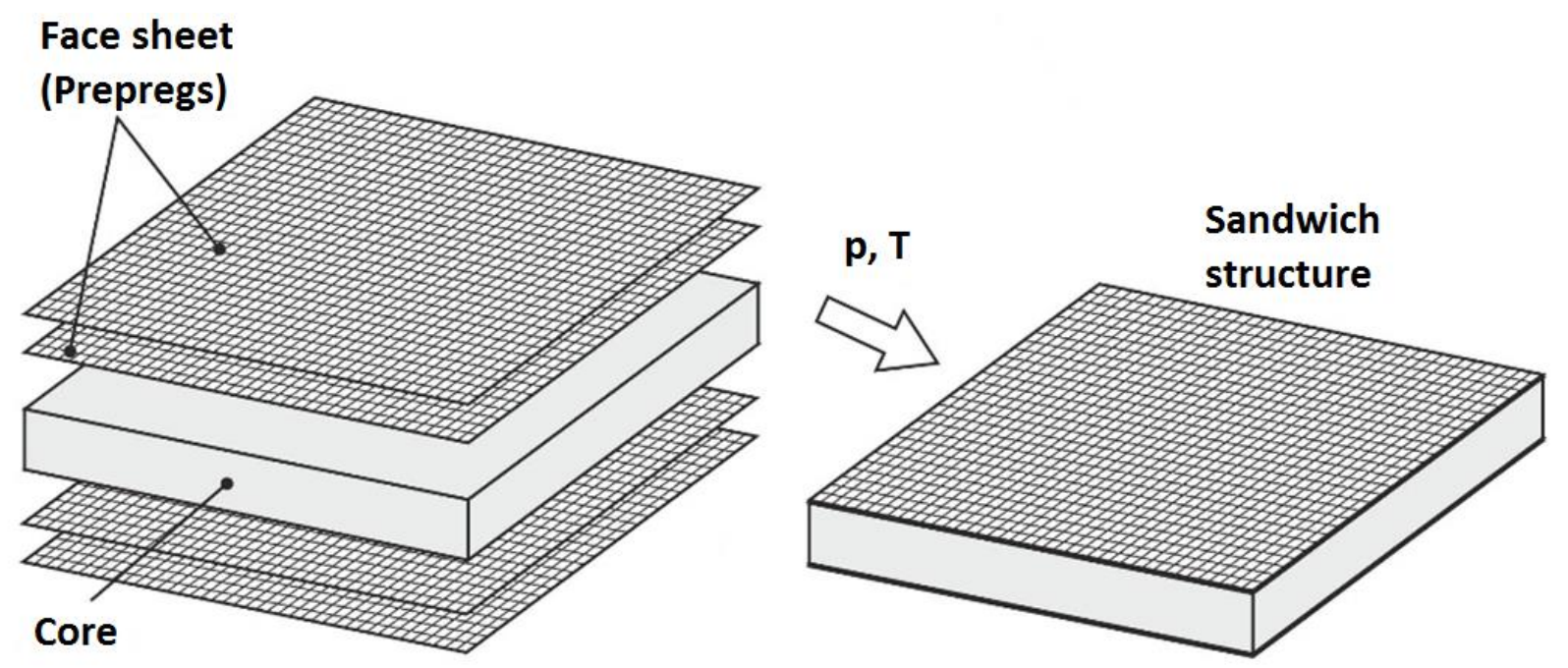

Fig. 1 Individual layers in traditional prepreg sandwich construction

In technical practice, a wide spectrum of materials that can be used as the face sheet (facing) of sandwich structure is available. Their selection depends especially on the specific application and desired properties. Generally, face sheet materials can be divided into two groups; metallic materials - thin plates particularly made of aluminum, steel, and metal alloys, and non-metallic materials fiber composites (glass, carbon, etc.) with different matrix (polyester, phenol, epoxy, etc.), HPL sheets, plywood and currently extensively used pre-impregnated materials (prepregs). Conversely, core materials used in sandwich applications can be divided into four main groups, namely metallic and polymer foams, metallic and non-metallic honeycombs, corrugated cores and natural core materials as cork and balsa. Individual types differ mainly in mechanical properties, availability, and thus by price. The main evaluated properties include density, shear strength and modulus, thermal and sound insulation properties. The connection of all parts can be ensured by adhesive layer that is available in form of foil adhesive or liquid type, applied by hand lay-up. The most commonly used adhesives are epoxides, polyesters or polyurethanes [10-14].

In general, sandwich structures are characterized by excellent mechanical properties at very low weight. On the other hand, sandwich concept selection brings also some problems related to its macrostructure $[8,15,16]$. The result of sandwich wall geometrical and material parameters is layered, and thus considerably inhomogeneous element, where some its aspects of mechanical behavior can vary considerably compared to conventional homogeneous wall [17].

\section{Bending Stiffness of Sandwich Structure - Effective Elastic Modulus}

Bending stiffness $\left(\mathrm{K}_{0}\right)$ of layered sandwich cross-section can be write due to engineering beam theory, also referred to as the Timoshenko beam theory:

$$
K_{O}=E_{1} J_{R}
$$

where: $E_{1}[\mathrm{MPa}]$ is bending modulus of faces, and $\mathrm{J}_{\mathrm{R}}\left[\mathrm{mm}^{4}\right]$ is quadratic moment of area of reduced cross-section [18], see Fig. 2. This reduced cross-sectional area of inhomogeneous (composite) elements is given by widths reduction of individual layers with respect to selected reference (typically the largest) value of elastic modulus of evaluated structure. 


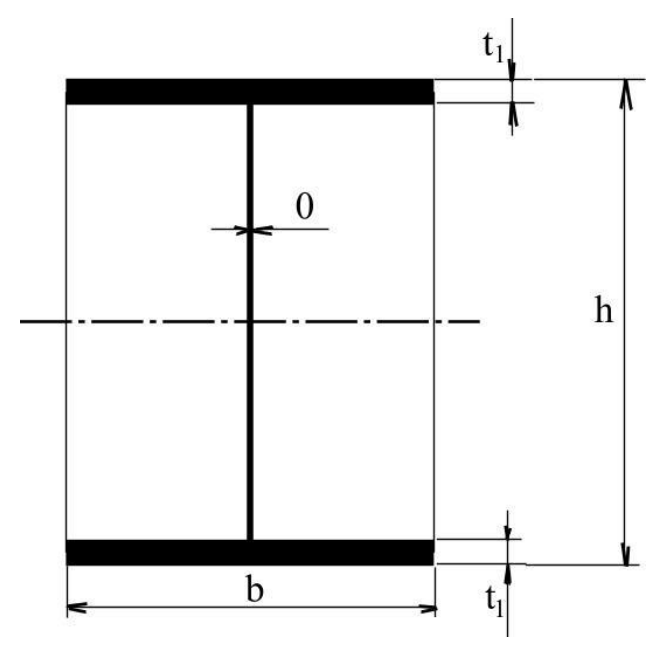

Fig. 2 Reduced cross-sectional area of three layer - sandwich wall

Due to this reduction, the bending stiffness is then:

$$
K_{0}=E_{1} \frac{b h^{3}}{12}\left[1-\frac{E_{1}-E_{2}}{E_{1}}\left(1-2 \frac{t_{1}}{h}\right)^{3}\right] \text {, }
$$

where: $\mathrm{E}_{2}[\mathrm{MPa}]$ is bending modulus of core, $\mathrm{t}_{1}[\mathrm{~mm}]$ is thickness of faces, $\mathrm{h}[\mathrm{mm}]$ is sandwich element thickness, and $\mathrm{b}[\mathrm{mm}]$ is sandwich element width [18].

When evaluating experimental results, new term - effective elastic modulus of sandwich structure $\left(\mathrm{E}_{\mathrm{ef}}\right)$ is introduced. It is defined as elastic modulus of thoughtfully homogeneous (single layer) wall of thickness equal to thickness of the sandwich structure, having the same value of bending stiffness as given sandwich structure. With respect to this assumption:

$$
E_{e f}=E_{1} \frac{12 J_{R}}{b h^{3}}
$$

The value of bending modulus arising from the standard bending test is probably the experimentally determined value of effective elastic modulus of a sandwich wall.

One of aspects of sandwich structure mechanical behavior is the impact of considerable shear yielding, i.e. low values of the foam core shear modulus on resulting - effective mechanical behavior of sandwich element. As is schematically shown in Fig. 3, the overall beam deformation in three-point bending test is beside deformation by mean of bending (normal) stresses also increased by relatively high effect of shear deformation. Therefore, shear stresses given by transverse forces in cross-section of sandwich element are transmitted as is well known in practice only by layer of expanded core. 


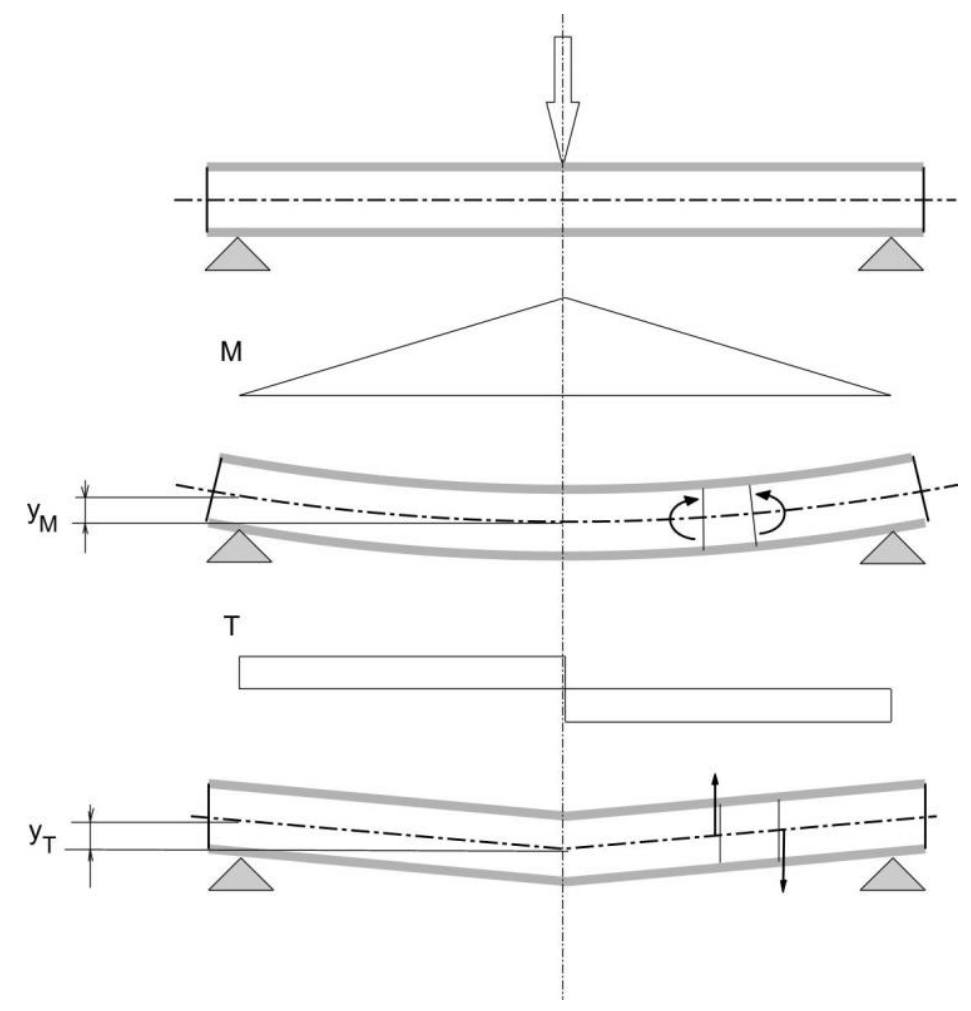

Fig. 3 Impact of core shear yielding on the overall deformation of sandwich beam in three-point bending test

Equations (1) and (2) respectively, including only deformation component given by bending stresses in load bearing faces, thus unlike homogeneous cross-sections always provide higher values of stiffness in comparison to experimentally measured. Analytical expression of deformation involving the core shear yielding, as shown in Fig. 2, can be further written:

$$
y_{M}+y_{T}=\frac{\partial A}{\partial F}
$$

where: A [J] is sum of deformation energy of bending moments and transverse forces [18].

\section{Experimental Testing of Sandwich Structures}

In order to verify results of numerical modeling, two types of sandwich structures were manufactured that differed in the used polymer core. Faces sheets were prepared from two layers of pre-impregnated E-glass fabric (prepreg) with areal weight of $296 \mathrm{~g} / \mathrm{m}^{2}$. Impregnation system in this prepreg is phenolic resin in total amount of $42 \mathrm{wt}$. \% [19]. Two prepreg layers in one face sheet are traditional for sandwich parts used in transportation [20].

As was mentioned, two types of polymer foam were selected as core material for sandwich beams (Fig. 4). First, polyethylenterephtalate (PET) foam with average density $100 \mathrm{~kg} / \mathrm{m}^{3}$ having compression modulus equal to $85 \mathrm{MPa}$ (Fig. 4A), and polyvinylchloride (PVC) foam with compression modulus of $70 \mathrm{MPa}$ and average density of $60 \mathrm{~kg} / \mathrm{m}^{3}$ (Fig. 4B) [21,22]. PVC foam core of $10 \mathrm{~mm}$ thickness and PET foam core of $10 \mathrm{~mm}$ and $20 \mathrm{~mm}$ were selected for sandwich experimental investigation. 

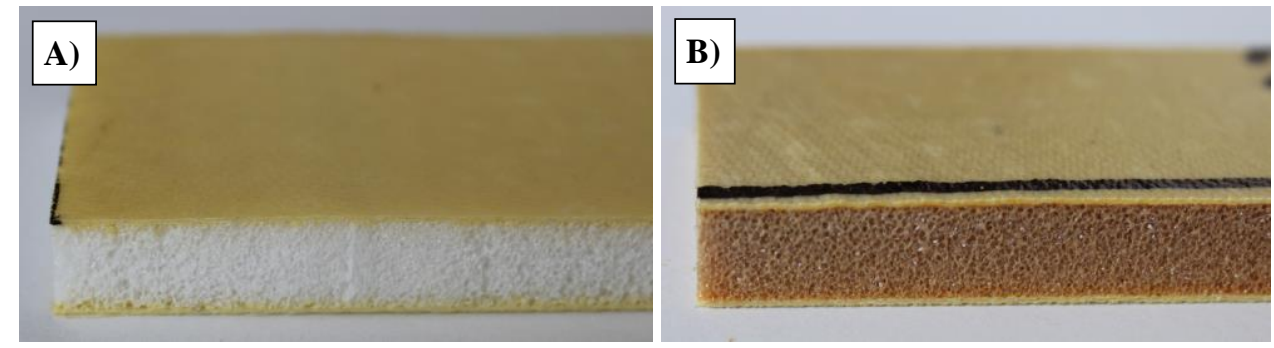

Fig. 4 Prepared sandwich beams

The materials were laminated together in the oven using vacuum bagging technology (vacuum pressure of 8 bar). The curing cycle consisted of $3{ }^{\circ} \mathrm{C} / \mathrm{min}$ ramp to $130{ }^{\circ} \mathrm{C}$, where the sandwich panels were cured for two hours.

After demolding of sandwich panel, testing specimens were cut using circular saw for standard bending tests. Dimensions of these sandwich beams (specimen) were chosen 210 x 45 mm with respect to core thickness. An experimental testing was conducted in three-point loading configuration with support span of $150 \mathrm{~mm}$. Test speed was set to $5 \mathrm{~mm} / \mathrm{min}$ according to ASTM C393 recommendation [23].

\section{Finite Element Prediction of Sandwich Beam Bending Behavior}

Numerical study of dependence of sandwich wall bending stiffness on foam core stiffness was conducted using COSMOS DesignSTAR software. In the study, linear elastic FEM model of threepoint bending test was used. The solution is performed as 2D linear elastic analysis of one half of three-point bending test symmetrical model as showed in Fig. 5. This figure depicts bending test of sandwich structure with $20 \mathrm{~mm}$ PET core. As can be seen from mesh deformation, core shear yielding have significant portion on overall sample deformation.

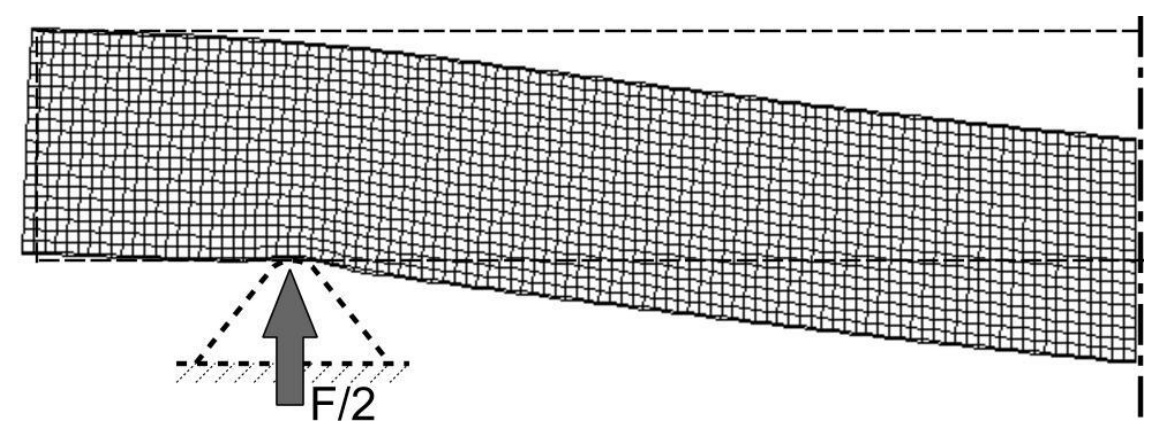

Fig. 5 Scheme of 2D linear elastic model

Resulting dependences for sandwich structures with 10 and $20 \mathrm{~mm}$ thick cores are given in following graph (Fig. 6). Values of effective elastic modulus are plotted for face sheet modulus of $22000 \mathrm{MPa}$ given by the producer and also verified by experimental measuring. As is evident, effective modules of both tested structures varies considerably (with respect to core thickness $-\mathrm{h}$ in $\mathrm{mm}$ ). Moreover, values of $\mathrm{E}_{\mathrm{ef}}$ calculated analytically based on (4) - dashed line are situated under values obtained by FEM modeling - continuous line, where in case of structures with $10 \mathrm{~mm}$ thick core is this difference even more significant. Same situation is can be seen for dependences of $E_{\text {ef }}$ on foam core stiffness. 


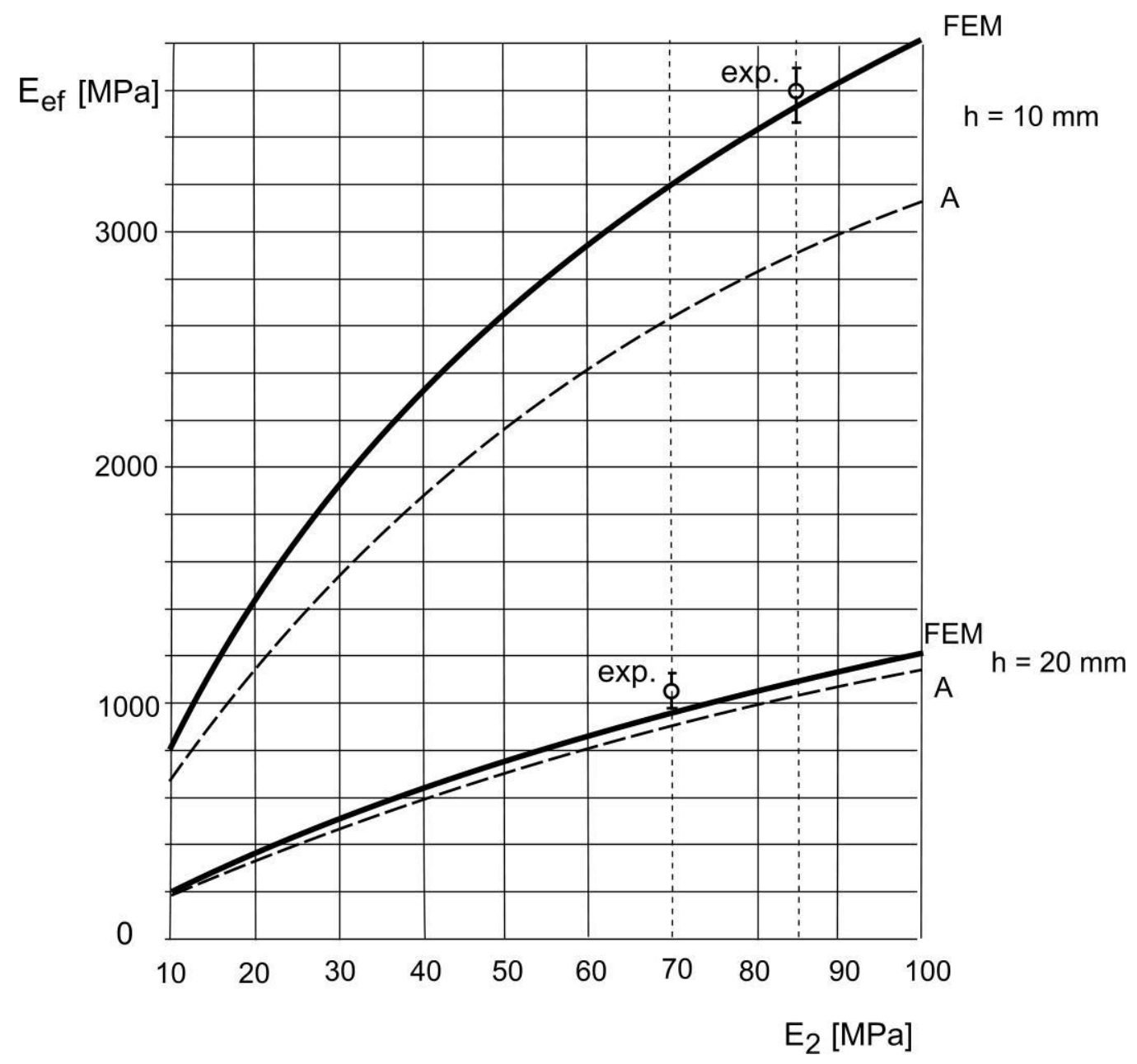

Fig. 6 Calculated dependencies of effective elastic modulus in three-point bending on foam core elastic modulus

Experimentally obtained arithmetic values of effective elastic modulus were equal to $1090 \mathrm{MPa}$ for sandwich structures with $20 \mathrm{~mm}$ PVC cores, $3620 \mathrm{MPa}$ for $10 \mathrm{~mm}$ PET cores respectively. Certain differences between the experimental and numerical values of sandwich bending stiffness can be attributed to secondary aspects - imperfections. These aspects include problem of precise determination of face sheet elastic modulus and its bi-modular behavior, errors in determination of core shear modulus and also local failure (indentation) in place of supports. The influence of shear yielding will decrease with growing support span.

\section{Conclusion}

The research has evaluated the influence of core elastic modulus on flexural stiffness of sandwich walls. The study shows mainly significant dependence of sandwich structure flexural stiffness during standard bending test on polymer core modulus. Differences of the sandwich effective stiffness in the real area of core elasticity modulus is in tenth of percent. Due to this fact, considerable differences may arise in three-point bending tests, depending on the parameters of individual test, especially in support span. Equally important is also detected relatively significant difference between the results of FEM modeling and analytical calculation based on Timoshenko beam theory of composite elements bending, and so to the detriment of analytically determined values. Performed experiments confirm this tendency, because of the good correspondence between with the results obtained by FEM simulation. 
As is apparent from presented study, it is necessary to devote great attention to the flexural stiffness of sandwich parts during their design and construction, especially to prevent possible failures in practical applications of these structures.

\section{Acknowledgement}

This study was supported by the internal grant of TBU in Zlín No.IGA/FT/2016/002 funded from the resources of specific university research.

\section{References}

[1] K.F. Karlsson, B.T. Åström, Manufacturing and applications of structural sandwich components, Composites Part A: Applied Science and Manufacturing. 28 (1997) 97-111.

[2] M. Mohamed, S. Anandan, Z. Huo, V. Birman, J. Volz, K. Chandrashekhara, Manufacturing and characterization of polyurethane based sandwich composite structures, Composite Structures, 123 (2015) 169-179.

[3] J. R. Vinson, The Behavior of Sandwich Structures of Isotropic and Composite Materials, first ed., CRC Press, New York, 1999.

[4] D. Zenkert, Nordic Industrial Fund, The Handbook of Sandwich Construction, EMAS Publishing, Worcestershire, 1997.

[5] L.J. Gibson, M.F. Ashby, Cellular solids: structure and properties, Cambridge University Press, Cambridge, 1999.

[6] S. Rusnakova, L. Fojtl, M. Zaludek, V. Rusnak, Design of material composition and technology verification for composite front end cabs, Manufacturing Technology. 14 (2014) 607-611.

[7] A. Zinno, E. Fusco, A. Prota, G. Manfredi, Multiscale approach for the design of composite sandwich structures for train application, Composite Structures. 92 (2010) 2208-2219.

[8] G. Belingardi, M.P. Cavatorta, R. Duella, Material characterization of a composite-foam sandwich for the front structure of a high speed train, Composite Structures. 61 (2003) 13-25.

[9] L. Liu, H. Wang, Z. Guan, Experimental and numerical study on the mechanical response of Nomex honeycomb core under transverse loading, Composite Structures. 121 (2015) 304-314.

[10] M. Giglio, A. Gilioli, A. Manes, Numerical investigation of a three point bending test on sandwich panels with aluminum skins and Nomex ${ }^{\mathrm{TM}}$ honeycomb core, Computational Materials Science. 56 (2012) 69-78.

[11] Y.-M. Jen, CH.-W. Ko, H.-B. Lin, Effect of the amount of adhesive on the bending fatigue strength of adhesively bonded aluminum honeycomb sandwich beams, International Journal of Fatigue, 31 (2009) 455-462.

[12] M. Garrido, J.R. Correia, T. Keller, Effects of elevated temperature on the shear response of PET and PUR foams used in composite sandwich panels, Construction and Building Materials. 76 (2015) 150-157.

[13] B. Han, K.-K. Qin, B. Yu, Q.-CH. Zhang, CH.-Q. Chen, T. J. Lu, Design optimization of foamreinforced corrugated sandwich beams, Composite Structures. 130 (2015) 51-62.

[14] A. Arteiro, A. L.M.A. Reis, P. J.R.O. Nóvoa, L. F.M. Silva, M. Zupan, A.T. Marques, Low velocity impact and flexural performance of sandwich structures with cork and polymer foam cores, Ciência \& Tecnologia dos Materiais. 25 (2013) 79-84. 
[15] J. Banghai, L. Zhibin, L. Fangyun, Failure mechanism of sandwich beams subjected to threepoint bending, Composite Structures. 133 (2015) 739-745.

[16] A. Cernescu, J. Romanoff, Bending deflection of sandwich beams considering local effect of concentrated force, Composite Structures. 134 (2015) 169-175.

[17] C.A. Steeves, N.A. Fleck, Collapse mechanisms of sandwich beams with composite faces and a foam core, loaded in three-point bending. Part I: analytical models and minimum weight design, International Journal of Mechanical Sciences. 46 (2004) 561-583.

[18] A.S. Saada, Elasticity: Theory and Applications, Pergamon Press Inc., New York, 1974.

[19] Information on http://gurit.fangle.co.uk/files/documents/PH840-300-42.pdf

[20] Information on http://www.gurit.com/files/documents/prepreg-brochurev3pdf.pdf

[21] Information on: http://www.3accorematerials.com/products/airex/airexreg-t $90 . \mathrm{html}$

[22] Information on http://www.3accorematerials.com/products/airex/airexreg-c70.html

[23] ASTM C393/C393M-11, Standard Test Method for Core Shear Properties of Sandwich Constructions by Beam Flexure, ASTM International, 2012. 